\title{
Espacialidade social urbana e imigração
}

\author{
Spatiality social urban and immigration
}

\section{André de Souza Silva}

Universidade do Vale do Rio dos Sinos- UNISINOS - São Leopoldo - Rio Grande do Sul - Brasil

Resumo: Sendo as cidades um mosaico de interesses altamente territorializados, a morfologia urbana corresponde à expressão física das correlações de forças dos seus agentes ao longo do tempo. Neste sentido, a pesquisa analisa, através da relação tipo-morfológica, o processo de urbanização de parte das cidades gaúchas por imigrantes europeus alemães, e verifica como sociedades são identificadas através da configuração espacial urbana e são influenciadas por estes padrões de apropriação e uso social do espaço urbano. Considera-se que a ação coletiva dos imigrantes germânicos em produzir e transformar o espaço urbano e alocar neste condições de ambiência, urbanidade e habitabilidade, adapta o lugar às suas necessidades. Mas, em contrapartida, o lugar the impõe limites e desafios que determinam padrões socioespaciais decorrentes da relação tipo-morfológica estruturadora. Como resultado, verifica-se que cidades são únicas e isto deve-se a fatores específicos que influenciam a relação tipo-morfológica, tais como: eventos históricos, meio ambiente, decisões políticas, movimentos culturais e aspectos socioeconômicos. Ou seja, atualmente, constata-se que parte significativa dos padrões socioespaciais são causa e conseqüência da configuração espacial urbana advindos desde a época da imigração alemã.

Palavras-chave: Tipo. Morfologia urbana. Imigração.

Abstract: As a mosaic of cities territorially highly interests, urban morphology corresponds to the physical forces of expression correlations their agents over time. In this sense, the research analyzes by type and morphological relationship, part of the urbanization process of the gaucho cities by German European immigrants, and checks how societies are identified through the urban spatial configuration and are influenced by these patterns of ownership and use social urban space. It is considered that the collective action of German immigrants in producing and transforming urban spaces and allocate this ambience conditions, urbanity and housing, the place fits your needs. But, on the other hand, the place it imposes limits and challenges that determine socio-spatial patterns resulting from the structuring type-morphological relationship. As a result, it is found that are unique cities and this is due to specific factors that affect the morphological-type relationship, such as historical events; environmental, political decisions, cultural movements and socio-economic aspects. That is, currently, it appears that a significant part of the socio-spatial patterns are cause and consequence of urban spatial configuration arising from the time of German immigration.

Keywords: Type. Urban morphology. Immigration. 


\section{Introdução}

De acordo com diferentes ritmos e temporalidades, as cidades constituem artefatos em constante processo de (trans)formação. Contudo, possuem certas recorrências que embora não sendo permanentes, são duráveis, e se mantêm ao longo dos anos, tais como o sistema de vias, o perímetro das quadras, o parcelamento do lotes, as ocupações de áreas predominantemente residenciais, determinadas atividades não-residenciais tradicionais e/ou de grande porte, a vegetação urbana, os mananciais hídricos etc. Portanto, cidades apresentam regularidades e recorrências, e essas, de acordo com o aporte conceitual e teórico adotado, podem ser analisadas. A possibilidade de capturar a essência tipo-morfológica urbana da organização socioespacial é ainda uma questão em aberto. Assim sendo, analisar a dinâmica de apropriação espacial vinculada às diferentes regras de combinações tipomorfológicas do ambiente construído em (trans)formação e em estabilidade se faz necessário. Para tanto, inicialmente, apresenta-se um quadro dos principais conceitos adotados na classificação da forma urbana através do tipo e do processo de produção e transformação do espaço urbano em termos morfológicos, i.e. a relação tipo-morfológica desde o ponto de vista da configuração espacial. Em decorrência analisam-se, desde o ponto de vista da relação tipo-morfológica, alguns paradigmas urbanos que refletem o processo histórico de imigração germânica no Rio Grande do Sul, período este, de profundas transformações socioespaciais e intensa urbanização, responsável pela (trans)formação das cidades como foco de interação entre forças sociais e o ambiente construído.

\section{Descrição, classificação e análise do sistema configuracional urbano}

É fato que o espaço cria uma relação entre função e significado social na forma do ambiente construído ordenando as relações entre as pessoas. Edificações, quadras, lotes, sistema de vias, praças, parques, dentre outros, são símbolos visuais importantes da sociedade, sendo que os modos pelos quais, individualmente e coletivamente, criam e ordenam o espaço, possibilitam reconhecer determinados padrões de organização social (HILLIER e HANSON, 1984, p. 1 - 25). Estas condições do ambiente construído conduzem a um problema peculiar na tentativa de entender de modo analítico o seu significado e efeito social (HILLIER et al, 1987, p. 233-250).

A análise determinística tão-somente em termos normativo, compositivo, construtivo e funcional do ambiente construído como artefato, deixa de considerar a real condição probabilística das implicações sociais da distribuição espacial das partes em relação ao todo que compõem a forma urbana (HILLIER et al, 1987b, p. 233-250). Há de se ponderar no estudo da forma do ambiente construído os efeitos sociais da relação entre os espaços gerados a partir da distribuição das formas, como de aproximação ou distanciamento, de continuidade e descontinuidade, de obstrução e permeabilidade física e visual, de agregação e segregação, de permanência e passagem, dentre outros.

Argumentos que consideram, em princípio, que não há efeito positivo ou negativo do arranjo espacial da forma do ambiente construído (em específico as edificações) junto às pessoas, estabelecem uma discutível proposição imaterial, em que o comportamento das pessoas é um elemento neutro e independente da condição morfológica do tecido urbano. Esta proposição consiste num modo pouco aceitável de determinismo amórfico, no qual o espaço é (des)socializado e a sociedade é (des)espacializada (HILLIER e HANSON, 1984, p. 26; HILLIER, 1997, p. 184).

Sendo as pessoas afetadas de algum modo pela forma do ambiente construído e não-construído, um estudo sobre o sistema de espaços abertos públicos gerado pela disposição espacial do conjunto de formas construídas e sua lógica social se faz necessário (HILLIER e HANSON, 1984, p. 1-25). Se - espaço aberto público urbano tem sua forma (proporções e dimensões) parcialmente definida pelo 
conjunto de formas construídas edificadas que encontram-se em seu perímetro, consequentemente, a disposição das formas construídas é importante para a composição do espaço aberto público, que por sua vez define as relações socioespaciais. Pode-se, portanto, inferir que as formas construídas possuem relação direta com a apropriação social do espaço, pois edificações são artefatos que estabelecem a necessária ordenação dos espaços abertos públicos.

\section{Relação tipo-morfológica}

A cidade - sendo um sistema configuracional composto por edificações e espaços abertos públicos - mantém, através da relação tipo-morfológica, parte significativa da dinâmica social urbana. Tanto a noção de tipo quanto de morfologia referem-se à idéia de classificação, conformando uma seleção de partes capazes de descrever similitudes e/ou diferenciações do ambiente construído urbano. A relação tipomorfológica pressupõe conhecer partes da forma urbana, e o modo (regra) como se relacionam (configuração) nas diferentes escalas identificadas, tais como as porções de espaço urbano com forma própria; o conjunto de elementos recorrentes com forma em comum; e, a articulação de diferentes formas construídas e espaços abertos públicos entre si. A relação tipo-morfológica remete ao conceito de gramática das formas (shape grammar) postulado por Stiny e Gips (1972), os quais consideram que toda e qualquer forma do ambiente construído é gerada a partir da aplicação de um conjunto de regras recursivas (recorrentes). Ou seja, relação tipomorfológica é a regra de articulação entre unidades de formas construídas (edificações, equipamentos, elementos marcantes, etc) e o espaço aberto público (KRAFTA, 2002).

Para Rossi (1995, p. 61) "(...) entre esses dois fatos, tipologia edilícia e morfologia urbana, existe uma relação binária e por em evidência essa relação pode levar a resultados interessantes". Rossi (1995) trabalha com a hipótese da cidade como artefato, como obra de arquitetura que cresce com o tempo. Segundo o autor, a forma agrega em si o caráter de todos os fatos urbanos, inclusive a sua origem. A forma de uma cidade é sempre uma forma de um tempo da cidade, e existem muitos tempos na forma da cidade.

Entendido como princípio relacional de atributos recorrentes entre partes capazes de explicar o todo, o conceito de tipo pode ser aplicado não apenas às edificações, mas também aos demais elementos que compõem a forma urbana. É algo típico, constante, que desempenha papel próprio da constituição da forma. Como exemplo, citam-se as relações análogas dos tamanhos de lotes, da ocupação do solo, dos recuos, da localização nas quadras, dentre outros aspectos, compondo uma variedade e, conseqüentemente, uma maior ou menor complexidade de tipos de tecidos urbanos (CANIGGIA e MAFFEI, 1981; VEIRECHE e PANERAI, 1983).

A recorrência de tipos em diferentes espaços, períodos e sociedades, possibilitam uma síntese tipológica. São os períodos de repetição que definem um tipo, e as mudanças (morfológicas) que estabelecem uma tipologia. Em outras palavras, a tipologia é o estudo da relação - no tempo e no espaço - de uma determinada forma com seus múltiplos referentes (tipos). Consiste na disposição dos principais atributos relacionais capazes de descrever a base do processo de concepção formal de um objeto, podendo conduzir à criação de vários objetos totalmente diferentes, porém, provenientes do mesmo tipo (ARGAN, 1984; MARTINEZ, 1991).

Constata-se que formas construídas não estão eternamente vinculadas a função para as quais foram geradas. Hoje, com a quantidade de prédios históricos, cuja existência perpetua-se e justifica-se na mudança de usos, nota-se que o tipo pode também ser mutável, adaptável à nova função. Neste sentido, em termos morfológicos, o tipo é dissociado de sua condição histórica, transpõe o lugar. O tipo é assimilável a uma forma base comum, não apenas como trama estrutural, mas como estrutura interna da forma, possibilitando infinitas variantes formais, e talvez a modificação estrutural do próprio tipo (MARTINEZ, 1991). 


\section{Morfologia urbana: abordagens analíticas}

Por morfologia urbana entende-se o estudo do processo de formação e transformação da forma urbana ao longo do tempo, ou num determinado período de tempo específico, de modo a entender, essencialmente, as implicações de reciprocidade entre os componentes físico-espaciais (lotes, ruas, tipologias edilícias e áreas livres) e o contexto sociocultural (AYMONINO, 1979; BUTINA-WATSON, 1987; CONZEN, 1988; DEL RIO, 1990; LAMAS, 1992).

A (trans)formação da forma urbana pode ser avaliada segundo sua qualidade e desempenho segundo diferentes aspectos (geométricos, relacionais, funcionais, simbólicos), sendo a tipológica, histórico-geográfica e configuracional as abordagens mais representativas.

Pioneira na abordagem tipológica, a escola italiana baseia-se no trabalho de Savério Muratori e seguidores (Gianfranco Caniggia, Gean Luigi Maffei, Aldo Rossi, Carlo Aymonino, Giancarlo Cataldi) com a identificação da tipologia das construções de Veneza. Centram-se na análise dos aspectos físicos por meio de descrições e classificações qualitativas da tipologia da forma urbana. Compuseram importante contribuição para a elaboração de um método de análise do tecido urbano e de uma teoria geral de base tipo-morfológica, valorizando a participação de outras disciplinas sociais nos estudos urbanísticos. A abordagem tipológica, a partir da definição de critérios de identificação e classificação sintética da variedade de formas existentes, se detém na regularidade, padrão e repetição dos tipos que compõem a forma urbana. Consiste numa síntese passível de generalizações a partir leitura analítica do aspecto formal, compositivo e funcional das edificações e do entorno.

Entender como se forma, cresce e se modifica a forma urbana enquanto processo é o enfoque da escola francesa, tendo em Jean Castex, Philippe Panerai, Jean-Charles Depaule, da Faculdade de Arquitetura de Versailles, seus principais autores. Nas pesquisas sobre tipologia edilícia e morfologia urbana apresentam contribuições originais atinentes à relação da cidade com o ambiente natural e o lugar, ao encontro da tradição nacional dos estudos de geografia urbana. Contribuem para os estudos morfológicos ao proporem indicações gerais e de diferentes níveis para um método de análise que considere desde a determinação da área de estudo, a classificação dos tipos e a respectiva descrição da tipologia predominante na área.

A escola britânica possui várias vertentes, sendo a histórico-geográfica (Michael Conzen, Jeremy Whitehand, Terry Slater) a mais representativa. Procuram captar os vínculos existentes entre a tipologia e a morfologia através do processo histórico e contemporâneo de transformação urbana. Os trabalhos de Conzen têm sido considerados referência para o entendimento da evolução morfogenética das cidades européias classificadas pelas suas características geométricas e períodos de formação. Conzen (1988) ao dividir a cidade em períodos morfológicos, faz uma análise das modificações ocorridas nas formas edificadas, nos lotes e planos de cidade.

Verifica-se, portanto, que a morfologia urbana pode ser analisada de muitas maneiras. Porém, todas as abordagens levam a um senso comum: o da leitura e compreensão dos elementos que compõem as partes da cidade para a estruturação do todo. Os aspectos analíticos presentes em todas as abordagens embora considerem atributos relativos à estrutura física, social e cultural da cidade para a compreensão de sua totalidade, partindo do entendimento das partes, não permitem uma análise capaz de captar a dinâmica implícita nas relações entre aspectos físicos e práticas sociais inerentes aos tecidos urbanos. Enquanto as abordagens citadas anteriormente buscam a representação explícita e descritiva da forma urbana, a abordagem configuracional urbana procurar revelar os processos espaciais que possuem alguma determinação social.

\section{Configuração urbana e padrões sociais de apropriação espacial}


A abordagem do sistema configuracional urbano se refere à disposição espacial física da estrutura construída da cidade que estabelece a relação entre a forma espacial e o comportamento social urbano (HILLIER e HANSON, 1984; RIGATTI, 1995; HOLANDA, 2002). Pressupõe a condição relacional através da qual elementos ou componentes de um sistema espacial (avenidas, ruas, praças, edificações etc) estão localizados e distribuídos. O conjunto espacial das partes do ambiente construído edificado e urbano produz um todo interdependente de relações, ou seja, uma configuração espacial. Assume-se que a abordagem configuracional da relação tipo-morfológica espacial e funcional do ambiente construído arquitetônico e urbano possibilita meios de representar e analisar as particularidades relacionais dos tipos do ambiente construído arquitetônico e urbano, permitindo examinar tipos diretamente vinculados à determinada morfologia urbana. Deste modo, é possível estudar conjuntamente a tipologia, a morfologia e a configuração espacial urbana em seus aspectos específicos. Trata-se de uma opção demonstrativa que possibilita construir esquemas e regras capazes de estabelecer a um recorte conceitual, teórico e metodológico específico, o fenômeno urbano abrangente da apropriação socioespacial. Com isso, abre-se o campo das alternativas de questionamento, análise e entendimento em torno da influência recíproca entre sociedade e espaço; da lógica socioespacial de adequação da forma urbana às necessidades das pessoas, que por sua vez, passa a influenciar o comportamento destas.

Cidades são compreensíveis através da relação dialética entre espaço construído e espaço social. Veireche e Panerai (1983) consideram que as cidades estão vinculadas a edificações públicas que se distinguem por seu aspecto, natureza simbólica e ideológica, além de suas funções. Estas edificações constituem os pontos particulares e os lugares de exceção que diferenciam tecidos urbanos. Segundo Rigatti (1993, p. 87-88), “(..) discutir a cidade só faz sentido se esta noção abarca tanto a forma construída como o uso social dado a este suporte físico. Os diversos arranjos morfológicos (...) em certa medida condicionam as formas de apropriação social do espaço urbano(...)". Para Hillier e Hanson (1984, p. 1-25) é fato que o espaço cria uma relação significativa entre função e significado social em edificações, ordenando as relações entre pessoas. Edificações, individualmente ou coletivamente, criam e ordenam o espaço, sendo possível o reconhecimento de diferentes sociedades a partir da forma urbana (HILLIER e HANSON, 1984, p. 1-25). Em suma, a sociedade deve ser descrita em termos de sua espacialidade intrínseca, enquanto que o espaço deve ser descrito em termos de sua sociabilidade intrínseca (HILLIER e HANSON, 1984, p. 26-52).

\section{Organização social do espaço}

Os estudos de Hillier e colaboradores se apóiam no fato de que as relações sociais estão intimamente vinculadas à configuração espacial. Isto porque o espaço urbano não é algo abstrato e desprovido de conteúdo social, tampouco a sociedade é desprovida de conteúdo espacial. A sociedade é o próprio espaço, ou seja, parte integrante da cidade, uma vez que as relações sociais são espaciais. Não há uma estratificação social e outra físico-espacial independentes. Em princípio, qualquer experiência espacial subentende uma experiência em potencial de organização social. Assim sendo, morar, passear, comprar, trabalhar são experiências urbanas de forte cunho social que depende fundamentalmente da forma do ambiente construído da cidade. Seja qual for o meio de organização social, desde as relações familiares, trabalho, atividades culturais, associações comunitárias etc, este depende, mesmo que indiretamente, de relações físicas espaciais para ocorrer. Como a sociedade necessita de um suporte espacial para existir, a forma construída urbana, em termos de sua organização socioespacial, pode ser um dos condicionantes que tende a influenciar a aglomeração de pessoas em determinadas áreas da 
cidade, concentração de atividades e assiduidade de usos dos espaços abertos públicos.

Um dos efeitos da organização social é o próprio espaço aberto público. Isto significa que o ambiente construído (edificações, quadras, lotes, sistema de vias, praças, parques ...) é um processo cumulativo cultural que, ao longo dos tempos, revela a história e os costumes da sociedade em que nele está inserida.

De um modo geral, várias sociedades são representadas tanto pelo tipo de configuração física, quanto pelo grau de ordenação espacial que representa uma distinção da dimensão cultural (LEVISTRAUSS apud HILLIER e HANSON, 1984, p. 1-25). Para Durkheim (1973, p. 303-372), o espaço é em todos os lugares uma função das formas de solidariedade social, e estas são em troca um produto da estrutura da sociedade.

Pessoas são influenciadas por uma constante e envolvente espacialidade na qual se constitui e concretizam-se ações sociais e relacionamentos (SOJA, 1985, p. 90). O espaço é um produto social e uma parte fundamental da estruturação material da vida social. Significa dizer que a espacialidade não pode ser apropriadamente entendida e teorizada a parte da sociedade e dos relacionamentos sociais, e, inversamente, que teoria social deve conter uma central e abrangente dimensão espacial (SOJA, 1985, p. 123).

A organização socioespacial está diretamente relacionada com a experiência urbana voltada à prática coletiva da urbanidade, que envolve aspectos diversos da vida social, tais como a maneira de se comportar e relacionar em público. A urbanidade, desde o ponto de vista da organização socioespacial, é responsável pela formação, manutenção e desenvolvimento contínuo de diversos códigos sociais e pode, dessa maneira, constituir-se em instrumento de coesão social entre diferentes pessoas. Muitos dos códigos são formais (leis, regulamentos) enquanto outros são informais (comportamentos, condutas, costumes). Considerando que a organização social pode ser diversificada, a urbanidade (vida pública) nas cidades serve como modo de reconhecimento dessa variedade, de conscientização a respeito de diferenças sociais e desenvolvimento de tolerâncias (KRAFTA, 2002).

\section{Leitura do espaço urbano segundo relações tipo-morfológicas: a cidade como foco de interação entre forças sociais e o ambiente construído}

Para se ter uma visão de como a morfologia urbana influenciou ao longo dos anos a apropriação socioespacial, faz-se necessário um apanhado geral da evolução urbana da cidade desde sua colonização. Deste modo, para descrever e entender a evolução morfológica da cidade, a partir de seu traçado precursor, foram compilados alguns mapas históricos, os quais forneceram um panorama geral da produção e transformação de sua estrutura espacial. Os dados de cunho histórico se basearam fundamentalmente no trabalho de WEIMER cuja obra relata a evolução urbana da imigração germânica sob o ponto de vista tipo-morfológico desde a imigração até os dias atuais.

A intensa urbanização gera um fenômeno urbano particularmente importante no Rio Grande do Sul, qual seja, o processo de urbanização de parte do território gaúcho por imigrantes europeus. Havia um modelo ordenador responsável pelo processo de ocupação do solo na região: a imigração. Esse modelo pretendia reforçar a hegemonia política e econômica do governo provincial, pois ao fixar o imigrante a terra, formaram-se colônias autosustentáveis, desencadeando incipientes núcleos urbanos. Este processo fomentou a pré-condição de um mercado consumidor na própria zona colonial, dinamizando posteriormente, a inserção da economia imigrante na economia rio-grandense. Criou-se com isso, um circulo virtuoso entre apropriação espacial urbana e aspectos socioeconômicos. Será visto que padrões de crescimento, bem como particularidades do processo, podem ser identificadas através da configuração espacial, que influencia padrões de apropriação e o modo dominante do uso social do 
espaço. Neste sentido, a pesquisa contempla as implicações sociais da morfologia urbana a partir dos modos de apropriação espacial, na medida em que existe uma interdependência entre a forma do ambiente construído e o meio social.

O governo provincial do Rio Grande do Sul, a partir de 1800, com terras cedidas pelo Império, funda várias colônias de imigrantes germânicos. A maioria das colônias criada nesta época deveria possibilitar a abertura das matas e viabilizar a economia (SILVEIRA e HERMANN in: VOGT; SILVEIRA: 2001, p. 227). O lote, a linha, as picadas, o adensamento populacional e a quantidade de equipamentos e serviços urbanos básicos, fixaram o traçado colôniavila dessas comunidades (BARROSO in: WEIMER, 1992, p. 43).

Weimer (1992) observa que cada família assentava-se sobre um lote próprio, pois as terras no Estado eram então parceladas e transformadas em propriedade privada. Nessas condições não seria possível reconstituir a aldeia germânica em sua forma tradicional. Os imigrantes alemães rejeitavam tamanha arbitrariedade por parte dos governantes, não entendendo, tampouco aceitando a ortogonalidade de precisão geométrica do traçado do sistema de vias. Contudo, foram através das limitações do planejamento luso (trechos das picadas que eram tortuosos, onde havia, vales, córregos, etc) que curiosamente os imigrantes germânicos tentavam definir as suas relações socioespaciais de vizinhança típicas da aldeia germânica em sua forma tradicional.

Para WEIMER (1992, p. 63-64) ao mesmo tempo em que gradativamente se estabelecia a forma do ambiente urbano, como conquista por parte do imigrante germânico, em contrapartida, liquidava o fundamento comunal da organização social das tradicionais aldeias comunitárias germânicas. O desafio era constituir pelo território rio-grandense formas urbanas as mais próximas possíveis da aldeia de origem, de modo que o colono germânicobrasileiro mantivesse sua identidade e relações de proximidade, co-presença e vizinhança nos núcleos urbanos.

\section{Implicações socioespaciais decorrentes} da (trans)formação do traçado precursor germânico

A origem da relação tipo-morfológica centro européia, segundo Weimer (1987, p. 101), parte de um espaço comunitário. Cada lote apresenta um núcleo onde estão implantadas as benfeitorias e a habitação, em posição de destaque, livremente ordenada entorno de um pátio, complementado por uma massa verde que forma a horta e o pomar para a subsistência (WEIMER, 1987, p. 107-108).

A relação tipo-morfológica em tradicionais aldeias germânicas resulta numa variedade tipológica conforme a região e a origem cultural. No contexto desta pesquisa, serão descritas as tipologias dos três principais centros de imigração germânica no Estado.

O Weiler consiste no tipo mais simples de aldeamento, sendo o conjunto de alguns poucos sítios. O seu crescimento desordenado gera um Haufendorf (aldeia-monte) ou um Punktdorf (aldeiaponto) que é a forma mais comum de aldeamento alemão de onde se originou a maior parte dos imigrantes germânicos. Via de regra, quando dois Weiler crescem em direção ao outro surge o tipo Strassendorf (aldeia-rua). Quando a rua alarga-se no meio da aldeia, formando um logradouro, cria-se um Angerdorf (aldeia-logradouro). Observa-se, em termos da leitura configuracional do espaço, que a relação tipo-morfológica tradicional dos aldeamentos germânicos apresenta sentido de territorialidade, na medida em que a forma desses espaços reflete como grupos socialmente identificados, reivindicam e defendem o território claramente marcado através do modo de apropriação espacial (fig. 1). 
Figura 1: Tipos básicos das aldeias germânicas

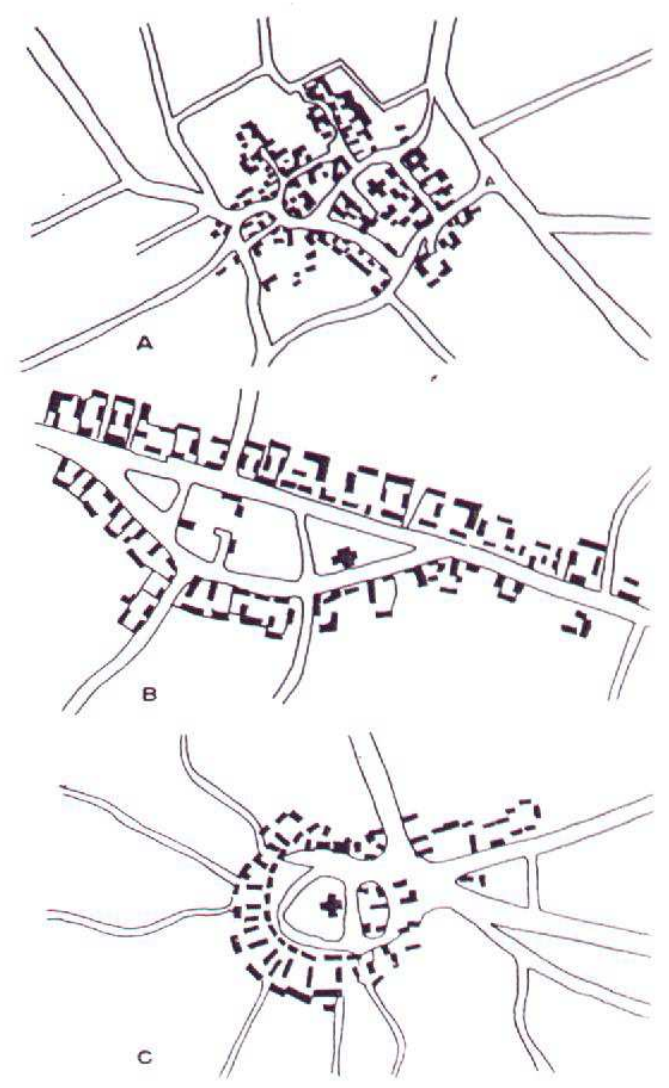

A - Haufendorf - aldeia monte e/ou Punktdorf - aldeia ponto B - Strassendorf - aldeia rua e/ou Angerdorf aldeia logradouro C - Rundling: aldeia arrendondada

Fonte: WEIMER, 1992, p. 59

A relação tipo-morfológica fundamental da maioria dos núcleos urbanos germânicos no Estado foi a Streusiedlung (povoação disseminada). Trata-se de uma forma de assentamento recente e bastante rara, encontrada em áreas ocupadas nos últimos séculos. Caracteriza-se por apresentar os sítios coloniais afastados uns dos outros, sem formar uma aldeia propriamente dita.

Enquanto as aldeias germânicas tradicionais estão arraigadas a cultura e a sociabilidade, no Rio Grande do Sul as formas urbanas adotadas seguem os preceitos lusitanos. Weimer (1992, p. 58) considera que "as condições de sua implantação certamente decorrem mais das condições locais dos assentamentos coloniais do que das formas culturais trazidas pelos imigrantes". Esta formação morfológica (ou morfogênese) reflete como diferentes culturas em diferentes lugares desenvolveram padrões particulares de forma urbana e de manifestações socioculturais, assim como, de que modo influenciaram a estrutura urbana das cidades de origem germânica no Estado.

A tentativa de reconstrução da aldeia germânica tradicional implicou em concessões devido às modificações infra-estruturais encontradas no Estado do Rio Grande do Sul. Se por um lado, a aldeia germânica tradicional era coletiva, cujos laços comunitários eram reforçados pela forma urbana que tendia ao círculo, por outro lado, os preceitos lusitanos entendiam o lote como propriedade individual e de posse privada, rigidamente definidos pela forma ortogonal retangular (WEIMER, 1987, p. 108).

O elemento que mais concorreu para a adaptação social da cultura germânica à nova realidade foi à posse da terra, ou seja a relação tipomorfológica e suas implicações socioespaciais. Neste contexto, o imigrante germânico não entendia, tampouco aceitava a concepção lusitana que estabelecia uma dicotomia entre campo e cidade, assim como a ortogonalidade da malha urbana que não respeitava as declividades naturais do sítio. Nas aldeias germânicas tradicionais, o tipo adotado era formado por casas próximas umas as outras, enquanto que o tipo das vilas lusitanas era geminado e/ou distanciado (WEIMER, 1987, p. 97). Nessas condições não seria possível reconstituir a aldeia na sua tipologia tradicional tampouco as relações socioespaciais. Este fato, segundo Weimer (1992), liquidava o fundamento comunal da organização tradicional das aldeias, aumentando o processo gradual de adaptação cultural ao lugar.

Há de se considerar que cada sociedade possui grupos espaciais de pessoas que vivem em proximidade umas com as outras, e grupos transespaciais cujo agrupamento de pessoas não depende da proximidade espacial, embora possa coincidir com um grupo espacial (DURKHEIM, 1973

\footnotetext{
${ }^{1}$ Partindo do princípio de que cada sociedade requer diferentes tipos de coesão social, Durkheim (1973) distinguiu dois princípios de solidariedade social: a solidariedade orgânica, baseada na interdependência por diferenças sociais de um grupo; e a solidariedade mecânica, baseada na integração por semelhanças sociais de um grupo. Durkheim (1973) considera
} 
HILLIER e HANSON, 1984). A organização do espaço urbano é análoga a função de solidariedade social tanto de grupos espaciais de pessoas, quanto de grupos transespaciais de pessoas, i.e., as sociedades se organizam em espaços com um maior ou menor grau de agregação e separação, gerando padrões de movimentos e encontros. Estes espaços são compostos por formas construídas, nos quais cada parcela da sociedade assume um padrão reconhecível de ordem espacial.

De modo a retratar sucintamente a produção social do espaço, e a transformação espacial da sociedade germânica no processo de consolidação da estrutura urbana no Estado, foram selecionadas algumas cidades (Novo Hamburgo, São Leopoldo e Santa Cruz do Sul), que refletem o modelo germânico de adaptação e apropriação urbana no Estado.

São Leopoldo foi fundada em um sitio baixo sujeito a inundações, possivelmente reflexo da implantação de um traçado ortogonal em terreno impróprio. Observa-se (fig. 2) que a expansão urbana da cidade pouco aproveita o desenho original (WEIMER, 1992, p. 67). A expansão do sistema de espaços abertos articulados em redes assume em São Leopoldo a forma de uma grelha ortogonal deformada, respeitando de certo modo as declividades do sitio de implantação. O tecido urbano desta cidade se origina a partir de poucos elementos e regras simples, entretanto adquire complexidade ao longo do tempo com a incorporação dos novos tipos edificados e modificações no espaço aberto público, resultando numa variedade dos tecidos urbanos.

que o espaço estabelece formas de solidariedade social e estas são em troca produto da estrutura da sociedade.
Figura 2: Primeiro traçado de São Leopoldo (a), e sua posterior expansão (b)
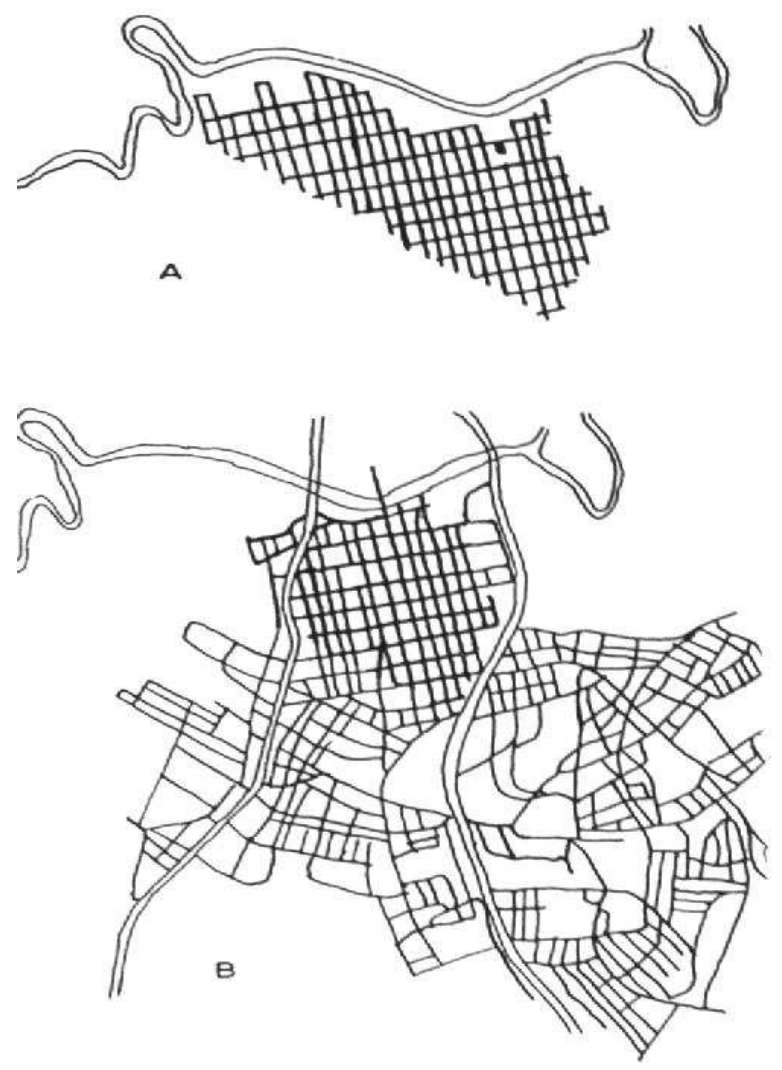

Fonte: WEIMER, 1992, p. 67.

Em Novo Hamburgo observa-se, segundo o levantamento de Ernest Monzel realizado em 1884, o traçado adaptado a topografia do terreno no Hamburgerberg, em contraste com a ortogonalidade das vias na planície de Novo Hamburgo (fig. 3). Hamburgerberg, que hoje vem a se constituir na parte histórica da cidade de Novo Hamburgo, surgiu em certas áreas que começaram a manifestar alguma densidade de formas construídas. O traçado precursor do núcleo urbano de Novo Hamburgo indica uma típica Haufendorf (aldeia ponto) com algumas poucas ruas irregulares, mas adaptadas à topografia local. Neste tipo de assentamento, as declividades do terreno são aproveitadas para tirar partido paisagístico do sistema de vias (WEIMER, 1992, p. 69). No entanto, trata-se de uma exceção, pois o traçado linear das picadas não favorecia a Haufendorf (aldeia ponto), consolidando gradativamente o tipo Strassendoerfer (aldeia rua) como o mais adaptado aos preceitos lusitanos. 
Figura 3. Novo Hamburgo com o traçado adaptado às declividades do sítio

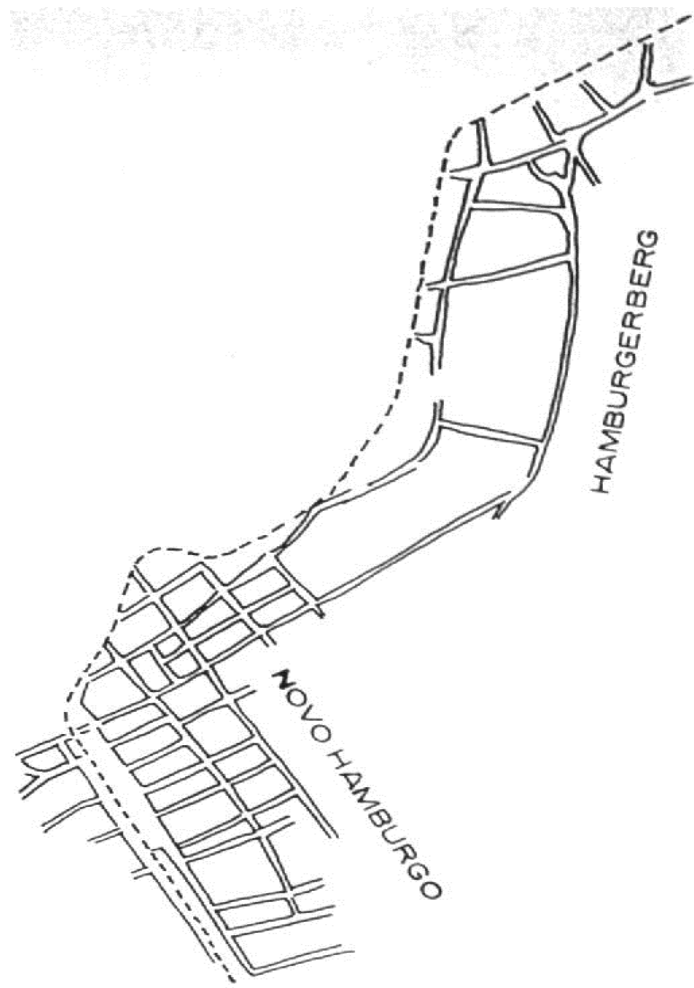

Fonte: WEIMER, 1992, p. 69.

No caso de Santa Cruz do Sul foram implantadas ruas ortogonais ao redor de uma praça central de acordo com as regras lusitanas (fig. 4). À medida que a cidade crescia, abandonava-se o plano inicial, e os bairros mais novos já não apresentam a mesma disposição regular de quadras. A forma urbana da cidade não é homogeneamente distribuída sobre o sítio de implantação, pelo contrário, apresenta graus de hierarquia viária diferenciada. Esta diferenciação no desenho urbano, de certo modo influencia 0 surgimento de tecidos urbanos importantes na cidade $e$ as condições de apropriações sociais diferenciadas do lugar.
Figura 4: Mapa de Santa Cruz do Sul

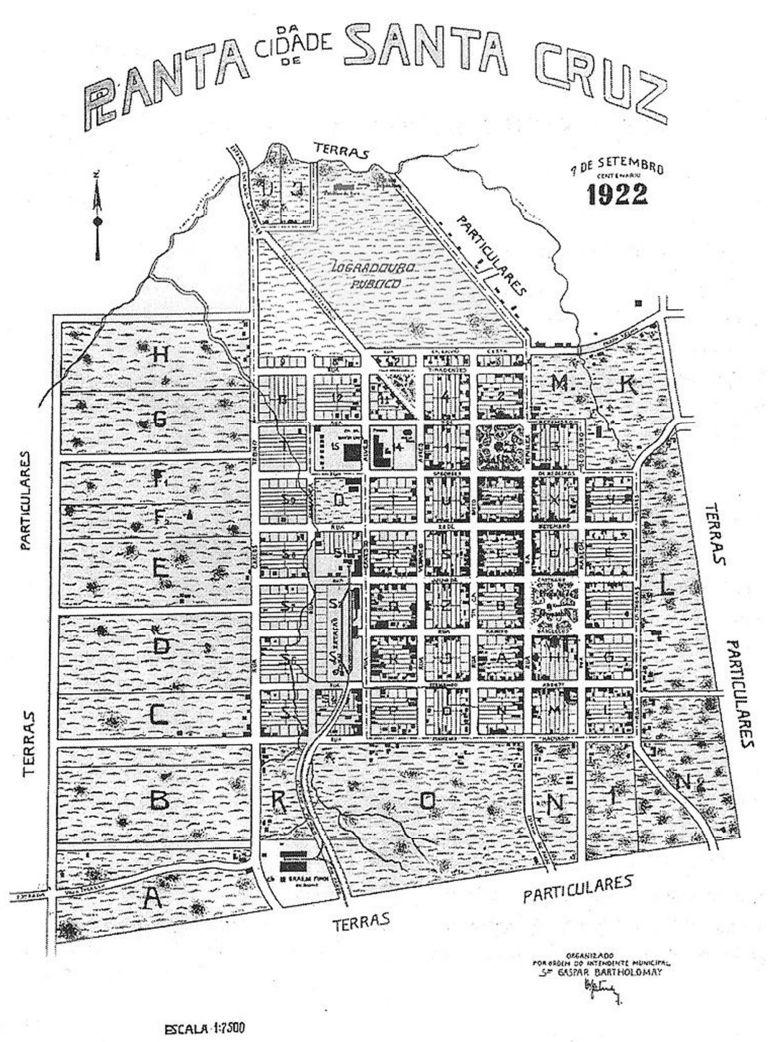

Fonte: Prefeitura Municipal de Santa Cruz do Sul.

\section{Legado da cultura alemã à fisionomia} urbana gaúcha: considerações finais

Diante do que se expôs, a partir da análise de três cidades com fortes traços de colonização germânica no Estado, verifica-se que gradativamente os traçados precursores destas cidades modificam sua configuração pautada nos referencias físicos, tradicionais e históricos da época da colonização lusitana. De algum modo, na medida em que os imigrantes germânicos se adaptavam ao lugar, preservavam e afirmavam na relação tipo-morfológica a cultura aldeã tradicional. Devido à articulação do sistema de vias das cidades, o crescimento e o desenvolvimento urbano possibilitou às novas áreas estabelecerem relações entre si e com o núcleo precursor. A estruturação morfológica ocorrida ao longo dos anos nestas cidades tende a reforçar cada vez mais a importância da relação tipo-morfológica como responsável pelo modo de apropriação socioespacial. Isto porque, cidades são únicas devido a influências de fatores específicos inerentes ao tempo e ao lugar no qual cresceram. 
Os imigrantes germânicos, em razão das regras estabelecidas pelo governo provincial lusitano da época, e do próprio desenvolvimento das cidades, desde sua colonização até os dias atuais, adaptavamse a um novo tipo de arranjo espacial, e influenciavam decisivamente a morfologia local. A ação coletiva dos imigrantes germânicos em produzir e transformar o espaço urbano e alocar neste, atividades sociais, adapta o espaço às suas necessidades, mas em contrapartida, o espaço the impõe restrições. Neste sentido, é altamente improvável que duas cidades repitam as mesmas influências de um grupo ou seqüência de fatos. Qualquer intervenção na cidade deve levar em conta obter, reforçar ou recriar determinados elementos culturais na sua estrutura física. Com isso, tanto a tipologia quanto a morfologia urbana refletem esta transformação social desde a imigração até os dias atuais.

A relação tipo-morfológica adotada pelo imigrante germânico, em contraponto aos preceitos lusitanos junto à forma urbana no Estado, é uma experiência de reinterpretarão socioespacial da conformação de sua aldeia rural de origem européia, com profundas adaptações em função de condicionantes do lugar.

Nenhuma cidade cresce aleatoriamente, possui lógicas parciais de agentes produtores do espaço urbano. Os agentes sociais necessitam de um suporte espacial, nisso surge a forma urbana, como resposta a uma necessidade social. Contudo, algumas dessas lógicas se sobrepõem a outras, de modo a manifestar no espaço aberto público e nas formas construídas algum tipo de ordenamento intencional. Percebe-se como as cidades germânicas tiveram dificuldades de adquirir expressão cultural própria. O momento histórico do surgimento das primeiras cidades germânicas no Estado condicionou tanto o surgimento e desenvolvimento da forma urbana, quanto à expressão espacial da cultura destas sociedades.

Tanto as tradicionais aldeias germânicas quanto as cidades analisadas são únicas e isto devese a fatores específicos que influenciam a relação tipo-morfológica, tais como: eventos históricos; meio ambiente, decisões políticas, movimentos culturais e aspectos socioeconômicos. Ou seja, parte significativa dos padrões socioespaciais atuais são causa e consequência da relação tipo-morfológica urbana advindos desde a época da imigração germânica no Estado.

\section{Referências}

AYMONINO, C. El significado de las ciudades. Barcelona: Blume. 1979.

ARGAN, G. C. Tipologia. In: Revista Summarios 79. Buenos Aires: Ediciones Summa. 1984.

BUTINA-WATSON, G. The use of urban history in the design of local urban areas. [S.I]: Urban Design Quaterly. no 25. Oxford Brookes University: Ashgate. 1987.

CANIGGIA, G., MAFFEI, G. L. Composizione Architettonica e Tipologia Edilizia. Letture dell'edilizia di base. Veneza: Marsilio Editori. 1981.

CONZEN, M. R. G. Morphogenesys, morphological regions and secular human agency in historic townscape. In: DENECKE and SHAW (ed) Urban historical geography. Cambridge: Cambridge University Press. 1988.

DEL RIO, V. Introdução ao desenho urbano no processo de planejamento. São Paulo: Pini, 1990.

DURKHEIM, E. Da divisão social do trabalho. In As regras do método sociológico. São Paulo: [s.n.] 1973.

HILLIER, B., HANSON, J. The social logic of space. Cambridge: Cambridge University Press. 1984.

HILLIER, B. The space is the machine. Cambridge: Cambridge University Press. 1997.

HILLIER, B., BURDETT, R., PEPONIS, J., PENN, A. Creating Life: Or, Does Architecture Determine Anything? Architecture and Behavior 3 (pp.: 233-250). 1987.

HOLANDA, F. O espaço de exceção. Brasília: EdUNB. 2002.

LAMAS, J. M. R. G. Morfologia Urbana e o desenho da cidade. Lisboa: Fundação Calouste Gulbenkian, 1992.

KRAFTA, R. Morfologia e infraestrutura urbana. Porto Alegre: [ARQ. 02213. Módulo de Morfologia urbana UFRGS - Departamento de Urbanismo], 2002.

MARTINEZ, A. C. Ensaio sobre el proyecto. Buenos Aires: Editorial, CP67, 1991. 
ROSSI, A. A arquitetura da cidade. São Paulo: Martins Fontes, 1995.

RIGATTI, D. Espaço da cidade e estruturação social. In PANIZZI, W. M. ROVATTI, J. F. (org.) Estudos urbanos - Porto Alegre e seu planejamento. Porto Alegre: EdUFRGS, 1993 (pp. 87-98).

Apropriação social do espaço público - um estudo comparativo. In Paisagem Ambiente Ensaios. São Paulo: [s.n.], no 7, Junho/1995, (pp 141-196).

SILVEIRA, R. L. L., HERMANN, E. As cidades e a urbanização do Vale do Rio Pardo. In: VOGT, O. P., SILVEIRA, R. L. (org.) Vale do Rio Pardo: (re) conhecendo a região. Santa Cruz do Sul: EdUNISC, 2001 (pp. 217-257).

SOJA, E. The spatiality of social life: towards a transformative retheorization, In: URRY \& GREGORY (ed). Social relations and spatial structures. London, MacMillan. 1985.

STINY, G., GIPS, J. Shape Grammars and the Generative Specification of Painting and Sculpture. In: FREIMAN, C. V. (ed), Proceedings of IFIP Congress 71, Amsterdam: North-Holland (pp.: 1460 - 1465). 1972.

VEIRECHE, M; PANERAI, P. Estructuras urbanas. Madrid: IEAL.1983.

WEIMER, G. A arquitetura da imigração alemã: um estudo sobre a adaptação da arquitetura centro européia no meio rural do Rio Grande do Sul. Porto Alegre: EdPUC, 1980.

A arquitetura rural da imigração alemã. In

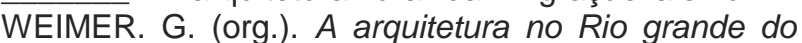
Sul. Porto Alegre: Mercado Aberto. 1987 (pp. 95-119).

Vida e morte da cidade teuto gaúcha. In WEIMER. G. (org.). Urbanismo no Rio Grande do Sul. Porto Alegre: EdUFRGS - Prefeitura Municipal de Porto Alegre, 1992. (pp. 57-73). 